\title{
Nueva reunión del Quad, en Tokyo: antecedentes y alcances
}

\section{Lucía Rubiolo'}

\section{Contribución en la Sección Debates Internacionales}

Resumen: Como se conoce, en medio de la campaña electoral de los Estados Unidos y de uno de los peores momentos de la relación entre Estados Unidos y la República Popular China, el Secretario de Estado Mike Pompeo tomó la decisión de acortar su viaje previsto a Japón, Mongolia y Corea del Sur (el viaje a esos últimos países se pospuso para fines de octubre), para entre el 4 y el 8 de octubre, concretando reuniones con los Ministros de Relaciones Exteriores de los países del denominado "Quad" (Australia, India, Japón, junto a Estados Unidos), entre el 4 y el 6 de octubre, en Tokio, a pesar de que la reunión original estaba planeada para realizarse en Nueva Delhi (India) (Toya, 2020). Este Diálogo Cuadrilateral de Seguridad, es un foro estratégico informal entre estos cuatro países, que mantienen encuentros/cumbres con cierta regularidad, al tiempo que realizan ejercicios militares e intercambian información. Fue iniciado en el año 2007, por el Primer Ministro de Japón, Shinzo Abe, como un diálogo, bajo la visión de un "arco de libertad y prosperidad" para los países ribereños de los océanos Índico y Pacífico. Ese grupo de países se había reunido en 2004 para la tarea de ayuda tras el tsunami del Océano Índico de ese año, formándose así la base del foro que se disolvió luego de finalizar los esfuerzos humanitarios.

Como se conoce, en medio de la campaña electoral de los Estados Unidos y de uno de los peores momentos de la relación entre Estados Unidos y la República Popular China, el Secretario de Estado Mike Pompeo tomó la decisión de acortar su viaje previsto a Japón, Mongolia y Corea del Sur (el viaje a esos últimos países se pospuso para fines de octubre), para entre el 4 y el 8 de octubre, concretando reuniones con los Ministros de Relaciones Exteriores de los países del denominado "Quad" (Australia, India, Japón, junto a Estados Unidos), entre el 4 y el 6 de octubre, en Tokio, a pesar de que la reunión original estaba planeada para realizarse en Nueva Delhi (India) (Toya, 2020).

Este Diálogo Cuadrilateral de Seguridad, es un foro estratégico informal entre estos cuatro países, que mantienen encuentros/cumbres con cierta regularidad, al tiempo que realizan ejercicios militares e intercambian información.

\footnotetext{
${ }^{1}$ Licenciada en Historia, es docente de la Universidad Nacional de Río Cuarto y miembro del Nodo de Estudios sobre Asia y África del Centro de Estudios y de Gestión en Redes Académicas (CEGRA, Universidad Nacional de Río Cuarto, Córdoba, Argentina). Correo electrónico: luciarubiolo@gmail.com
} 
Fue iniciado en el año 2007, por el Primer Ministro de Japón, Shinzo Abe, como un diálogo, bajo la visión de un "arco de libertad y prosperidad" para los países ribereños de los océanos Índico y Pacífico. Ese grupo de países se había reunido en 2004 para la tarea de ayuda tras el tsunami del Océano Índico de ese año, formándose así la base del foro que se disolvió luego de finalizar los esfuerzos humanitarios. En 2006, el entonces Primer Ministro de la India, Manmohan Singh, realizó una declaración conjunta con Japón, señalando que: "El contexto actual de las relaciones Japón-India se basa en sus percepciones similares del entorno en evolución en la región y el mundo en general. Está impulsado por la convergencia de intereses y aspiraciones políticos, económicos y estratégicos a largo plazo y preocupaciones y respaldado por un compromiso común con la democracia, la sociedad abierta, derechos humanos, estado de derecho y economía de libre mercado. Se basa en un profundo respeto por las contribuciones de otros a la promoción de la paz, la estabilidad y el desarrollo en Asia y más allá, libre de diferencias históricas" (Joint Statement Towards JapanIndia Strategic and Global Partnership, 2006, pár. 5), agregando que "(ambos países) tienen responsabilidad y son capaces de responder a los desafíos, y deben desempeñar un papel activo en la promoción de la paz y la estabilidad en Asia y el mundo en general" (pár. 6). Ello fue seguido a su vez por un encuentro "exploratorio" de altos funcionarios de los 4 países en los márgenes del Foro Regional de la ASEAN, que se realizó en Manila, en 2007 (Chellaney, 2007).

Aquella primera versión inicial del Quad registró el retiro de Australia, en 2008, tras una protesta diplomática de China ante la realización de ejercicios navales de Malabar con Singapur (One India, 2007). Por lo demás, ha habido otras reacciones filosas de China frente a la participación en estos ejercicios, siendo un ejemplo de ello las manifestaciones del portavoz del Ministerio chino de Relaciones Exteriores, Hong Lei quien, ante la inclusión de Japón en los ejercicios celebrados entre Estados Unidos e India, comentó que "Nuestra posición es muy clara. Se espera que el país en cuestión no provoque enfrentamientos y aumente las tensiones en la región" (The Economic Times, 2018, pár. 2).

En 2016, el Primer Ministro Abe, se refirió a la "Estrategia Indo-Pacífico libre y abierto", durante la sexta Conferencia Internacional de Tokio sobre el Desarrollo Africano (TICAD VI), aludiendo a "la importancia de lograr un orden marítimo libre y abierto basado sobre el estado de derecho en la región del Indo-Pacífico, que se extiende desde Asia-Pacífico a través del Océano Índico hasta Oriente Medio y África” (Ministry of Foreign Affairs of Japan, 2019, pár. 1).

La iniciativa fue retomada en 2017, buscando profundizar la cooperación en seguridad, al tiempo que coordinar alternativas a la financiación de la infraestructura regional ofrecida por el régimen chino (Toya, 2020). Cabe recordar que ese año, la administración 
Trump lanzó su primera Estrategia de Seguridad Nacional, en la que enfatizó la importancia de la región del "Indo-Pacífico" (en vez de la de "Asia-Pacífico"), señaló que se buscaría profundizar la cooperación con Japón, Australia e India y se adoptó un tono más duro con China (USA Government, 2017, p. 46).

Los ministros de Relaciones Exteriores de los países se habían reunido en 2019, en Nueva York, aprovechando los márgenes de una Asamblea General de las Naciones Unidas. Hasta 2019, las reuniones del foro se desarrollaban a nivel de Subsecretario, por lo que puede decirse que en la reunión de este año se registró un gran avance (Roy, 2019).

La última reunión en Tokyo, llega en un momento complejo en cuanto a la relación con China. Los países del Quad se muestran desconfiados frente a lo que consideran expansionismo chino, manifestado de diversas maneras. Por su parte, Australia, publicó en julio de este año su Estrategia de Defensa, en ella señala que el gobierno fijó tres nuevos objetivos estratégicos para guiar la planificación de la Defensa: (1) dar forma al entorno estratégico de Australia, (2) disuadir acciones contra los intereses de Australia y (3) responder con fuerza militar creíble, cuando sea necesario (Australian Government. Department of Defense, 2020) y distintos medios indican que la India decidió invitar a este país a la realización de los ejercicios Malabar, en noviembre de este año. Habrá que esperar a noviembre para ver si tal invitación se hace efectiva y si Australia la acepta (Dziedzic y Oaten, 2020; Gurjar, 2020).

Mientras tanto, la reunión en Tokyo no tuvo una voz unívoca: Mike Pompeo señaló que "Como socios en este Quad, ahora es más crítico que nunca que colaboremos para proteger a nuestra gente y socios de la explotación, corrupción y coerción del Partido Comunista Chino" (Kuhn. 2020, pár 5), mientras que los restantes países eligieron no confrontar directamente con China.

Por su parte, el portavoz del Ministerio de Relaciones Exteriores de China, Wang Wenbin, expresó que "en lugar de formar camarillas exclusivas, la cooperación multilateral y plurilateral debe ser abierta, inclusiva y transparente" (pár. 12).

Más allá de las especulaciones que puedan hacerse acerca de la posible evolución de este foro, la realidad al día de hoy es que la reunión del Quad concluyó sin el anuncio de ninguna iniciativa de importancia. Al menos por ahora, las expectativas de estos encuentros resultan mayores que las acciones efectivas. 


\section{Referencias}

Australian Government. Department of Defense (2020). 2020 Defence Strategic Update Factsheet. https://www.defence.gov.au/StrategicUpdate2020/docs/Factsheet_Strategic_Update.pdf

Chellaney, B. (7 de junio de 2007). Playing the new Great Game in Asia and beyond. The Japan Times.

https://www.japantimes.co.jp/opinion/2007/06/07/commentary/playing-the-newgreat-game-in-asia-and-beyond/

Dziedzic, S. y Oaten, J. (14 de julio 2020). Australia likely to join Malabar naval exercises with India, US, Japan as part of China 'containment' strategy. ABC News. https://www.abc.net.au/news/2020-07-15/australia-set-join-india-us-japanmalabar-naval-exercise-china/12455576

Gurjar, S. (10 de agosto de 2020). Malabar Naval Exercises \& the Australia question. Madras Courier. https://madrascourier.com/opinion/malabar-naval-exercises-theaustralia-question/

Joint Statement Towards Japan-India Strategic and Global Partnership (2006). https://www.mofa.go.jp/region/asia-paci/india/pdfs/joint0612.pdf

Kuhn, A. (6 de octubre 2020). Pompeo Rails Against China At 'Quad' Meeting With Foreign Ministers In Tokyo. NPR. https://www.npr.org/2020/10/06/920683263/pompeorails-against-china-at-quad-meeting-with-foreign-ministers-in-tokyo

Ministry of Foreign Affairs of Japan (2019). Diplomatic Bluebook 2019. Special Feature: To achieve "A free and open Indo-Pacific". https://www.mofa.go.jp/policy/other/bluebook/2019/html/chapter1/c0102.html\#sf0 1

One India (29 de julio de 2007). Singapore to take part in Indian navy exercise. One India. https://www.oneindia.com/2007/07/29/singapore-to-take-part-in-indian-navyexercise-1185712420.html?utm_medium=Mobile\&utm_source=OIEN\&utm_campaign=Topic-Article

Roy, S. (23 de septiembre de 2019). Quad to meet: Foreign Ministers of India, US, Japan and Australia. The Indian Express. Recuperado de https://indianexpress.com/article/world/quad-to-meet-foreign-ministers-of-indiaus-japan-and-australia-6019411/ 
USA Government (diciembre de 2017). National Security Strategy of the United States of America.: USA Government. https://www.whitehouse.gov/wpcontent/uploads/2017/12/NSS-Final-12-18-2017-0905.pdf

Toya, B. (4 de octubre de 2020). El viaje de Pompeo a Asia Oriental se pospone pero la reunión del Quad sigue adelante. La Gran Época. https://es.theepochtimes.com/el-viaje-de-pompeo-a-asia-oriental-se-posponepero-la-reunion-del-quad-sigue-adelante_734533.html

The Economic Times (12 de julio de 2018). China reacts sharply to Japan's inclusion in Malabar exercises. The Economic Times.

https://economictimes.indiatimes.com/news/defence/china-reacts-sharply-tojapans-inclusion-in-malabar-exercises/articleshow/50172813.cms 